\title{
Summary of Stirling Convertor Testing at GRC
}

\author{
Jeffrey G. Schreiber ${ }^{*}$ \\ NASA Glenn Research Center at Lewis Field,Cleveland,Ohio, 44135
}

The NASA Glenn Research Center (GRC) has been testing free-piston Stirling convertors for potential use in radioisotope power systems. These convertors tend to be in the 35 to 80 watt electric power output range. Tests at GRC have accumulated over 80,000 hours of operation. Test articles have been received from Infinia Corporation of Kennewick, WA and from Sunpower of Athens, OH. Infinia designed and built the developmental Stirling Technology Demonstration Convertors (TDC) in addition to the more advanced Test Bed and Engineering Unit convertors. GRC has eight of the TDC's under test including two that operate in a thermal vacuum environment. Sunpower designed and developed the EE35 and the Advanced Stirling Convertor (ASC). GRC has six of the EE-35's and is preparing for testing multiple ASC's. Free-piston Stirling convertors for radioisotope power systems make use of non-contacting operation that eliminates wear and is suited for longterm operation. Space missions with radioisotope power systems are often considered that extend from three to 14 years. One of the key capabilities of the GRC test facility is the ability to support continuous, unattended operation. Hardware, software, and procedures for preparing the test articles were developed to support these tests. These included the processing of the convertors for minimizing the contaminants in the working fluid, developing a helium charging system for filling and for gas sample analysis, and the development of new control software and a high-speed protection circuit to insure safe, round-the-clock operation. Performance data of Stirling convertors over time is required to demonstrate that a radioisotope power system is capable of providing reliable power for multi-year missions. This paper will discuss the status of Stirling convertor testing at GRC. 


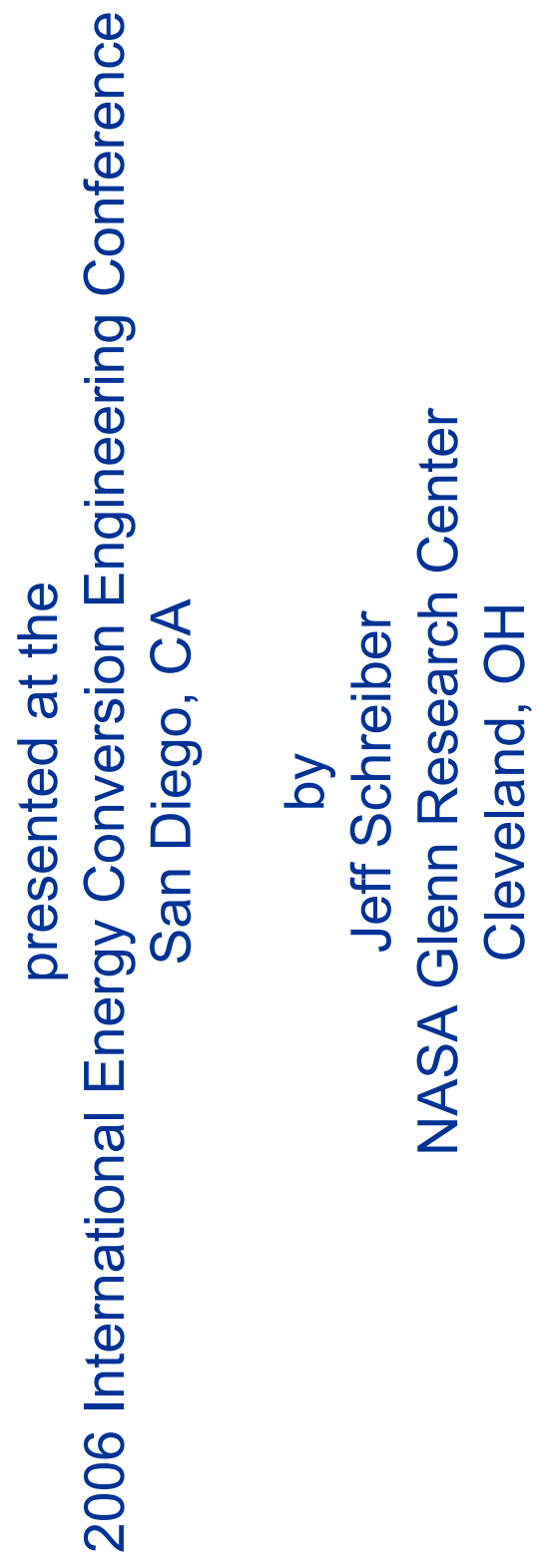




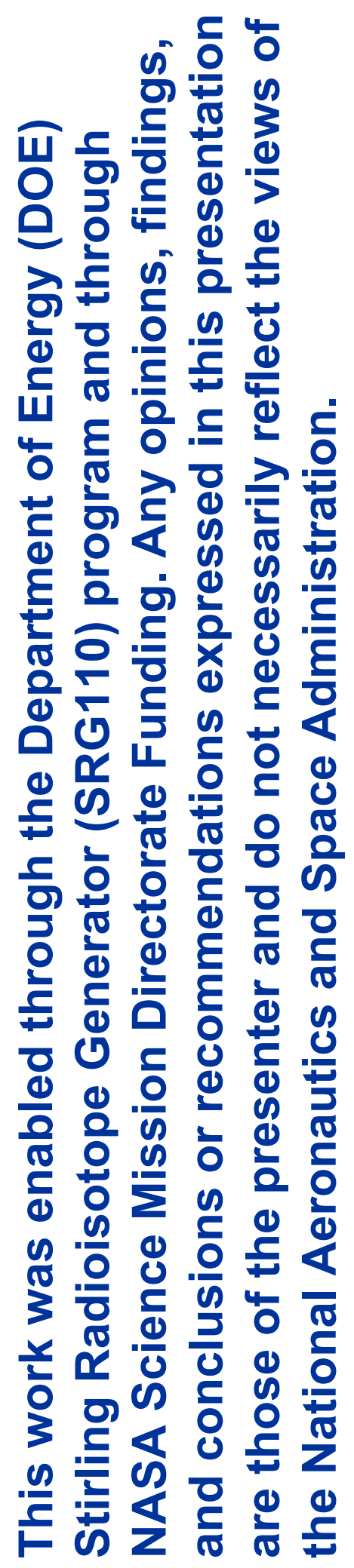




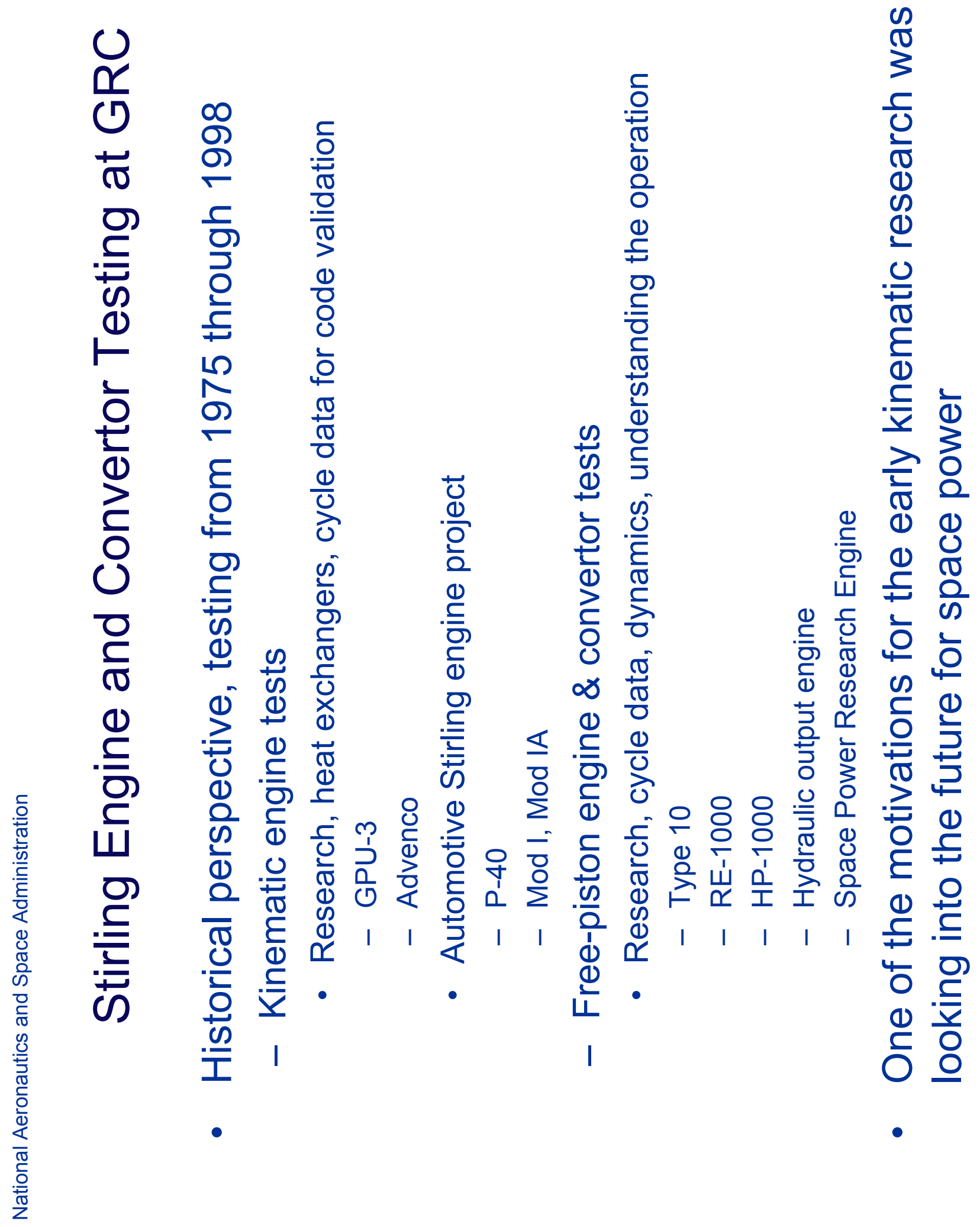


कृ

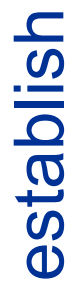

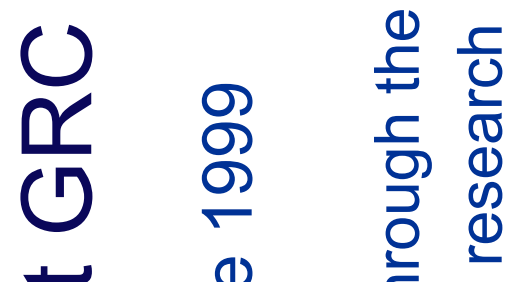

ब

○) ज 응 은

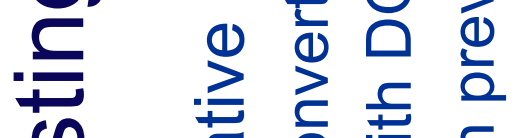

(1)

$\frac{?}{\frac{\overline{0}}{\overline{0}}}$

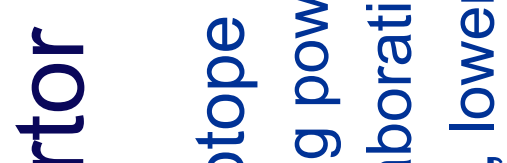

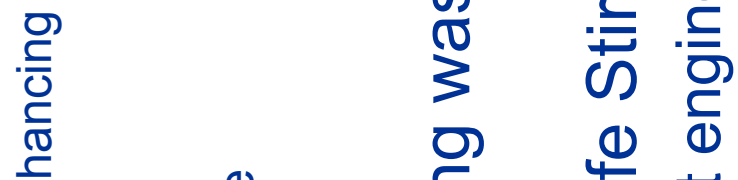

(1) 0 응

¿ 1 응

बे $\frac{0}{\omega}$ वे

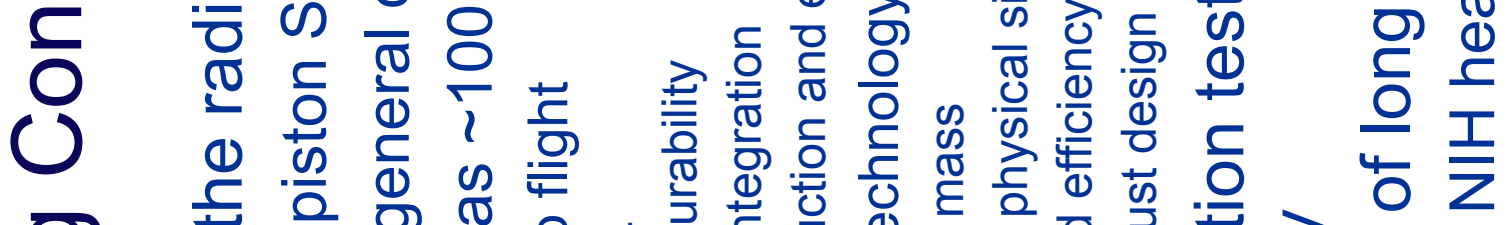

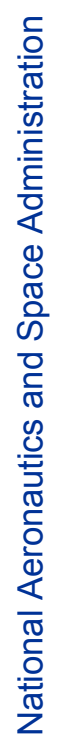

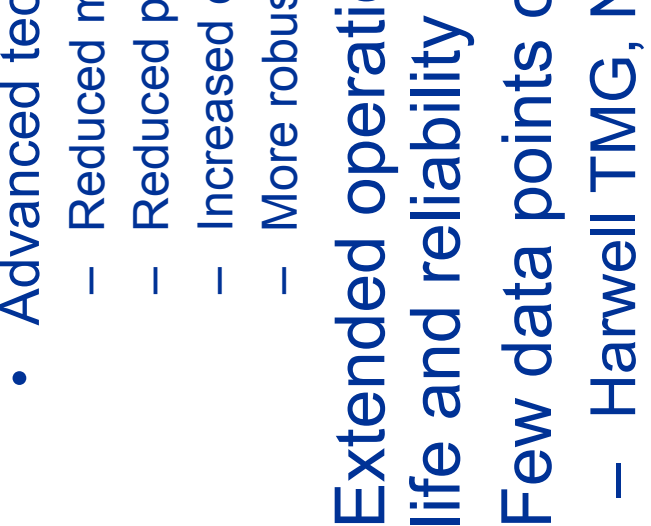




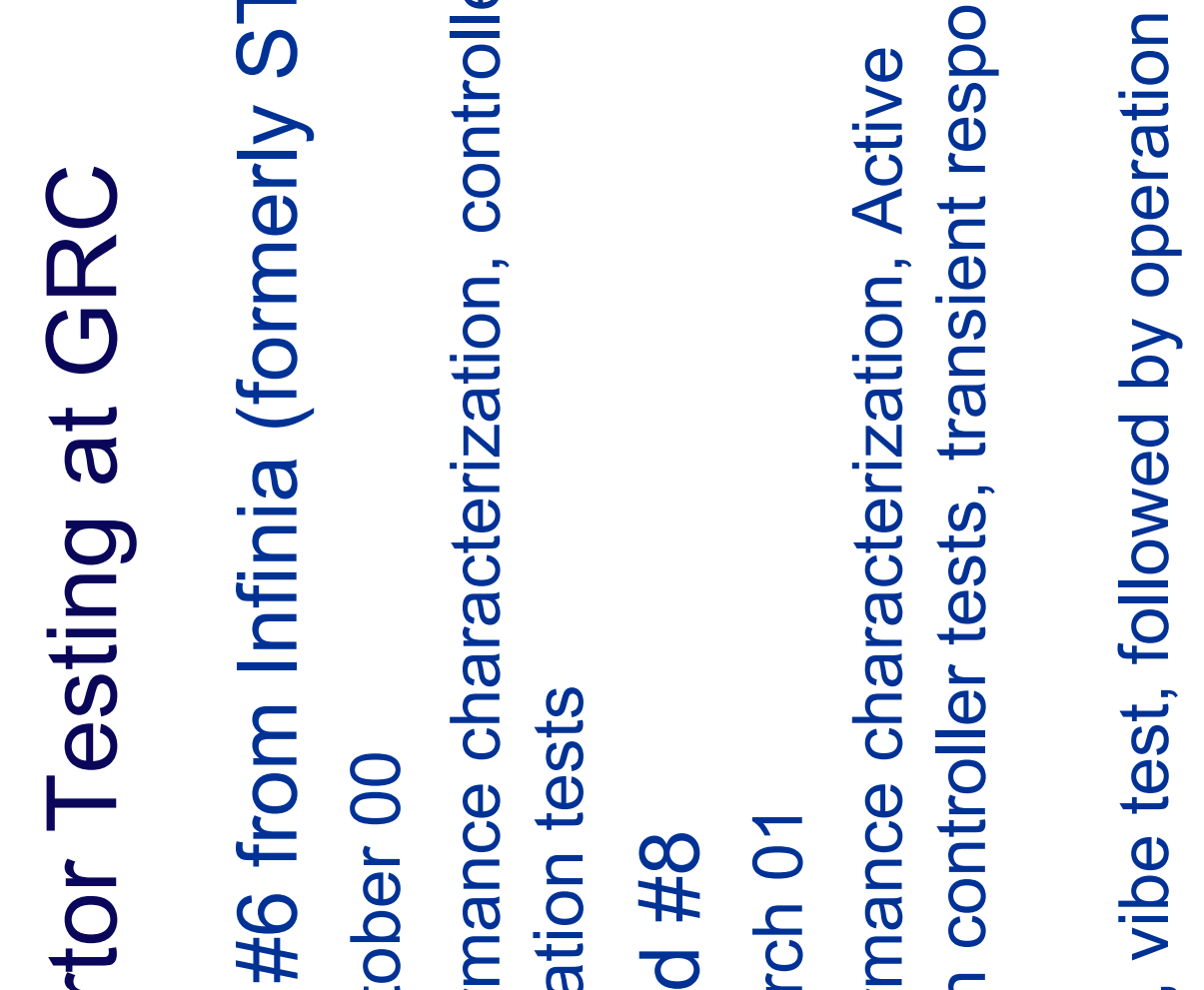

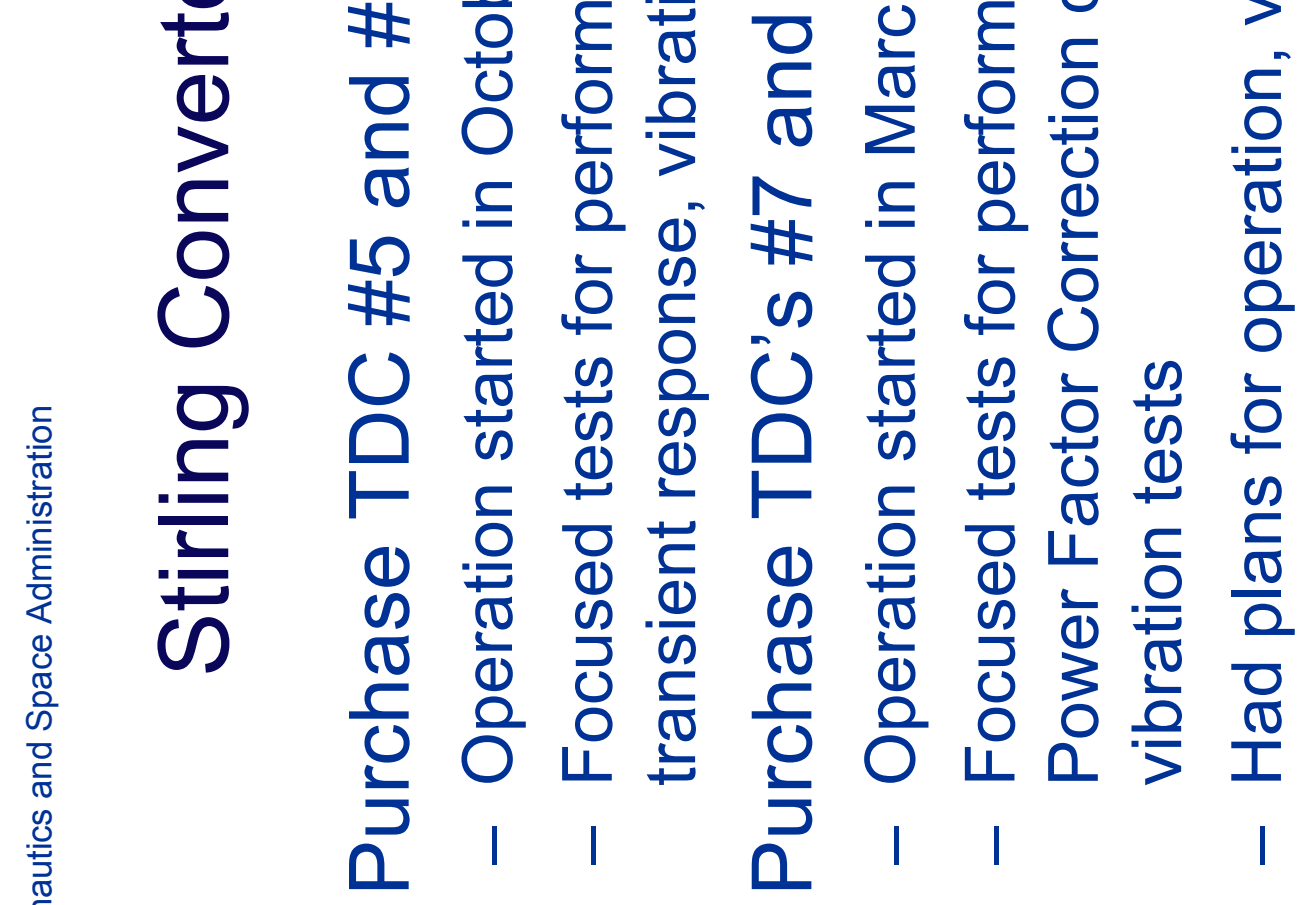



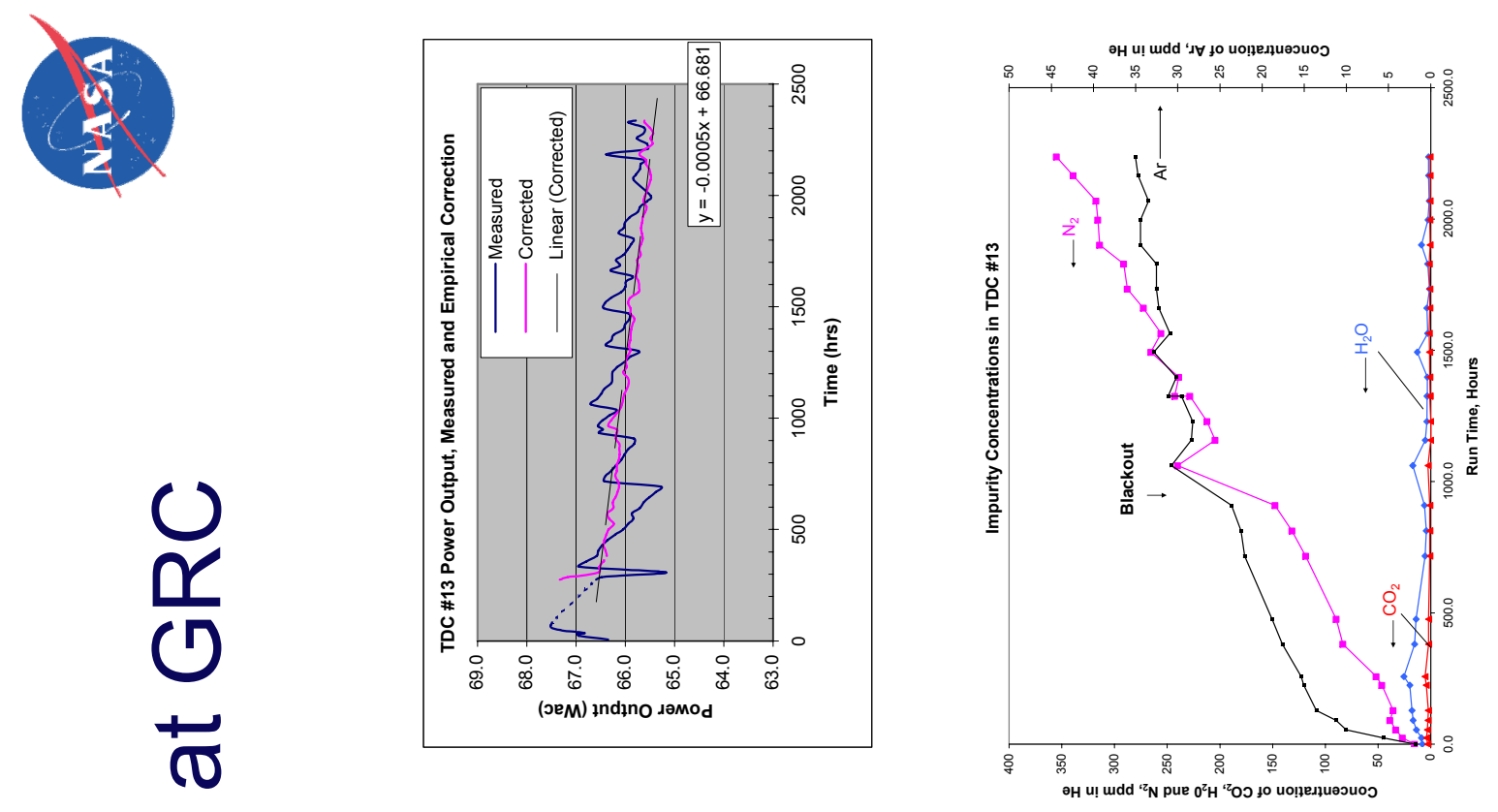

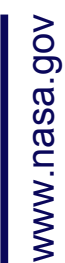

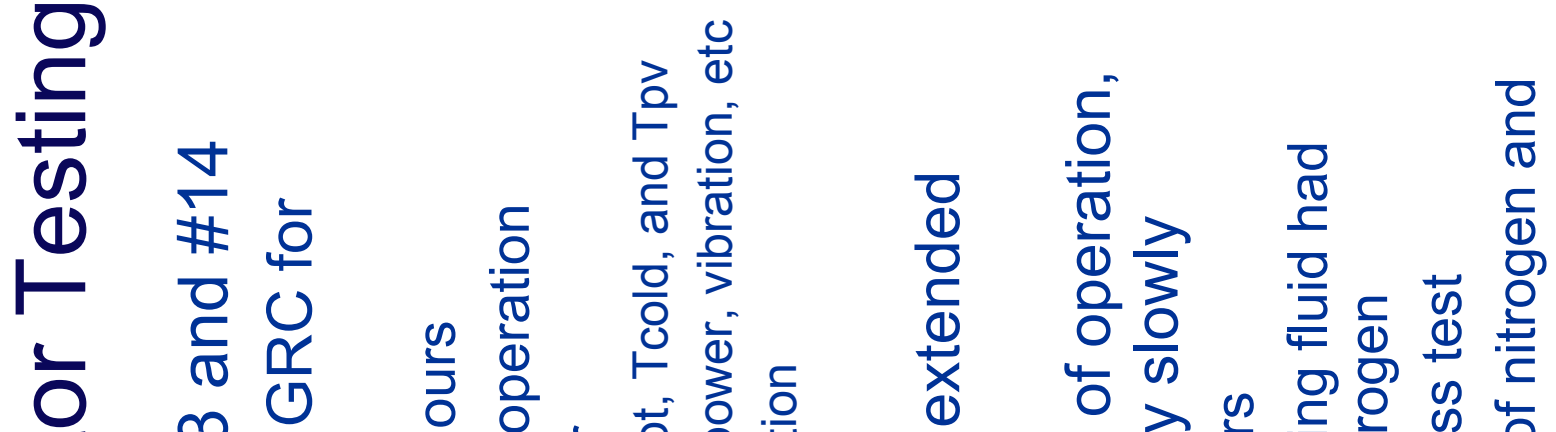

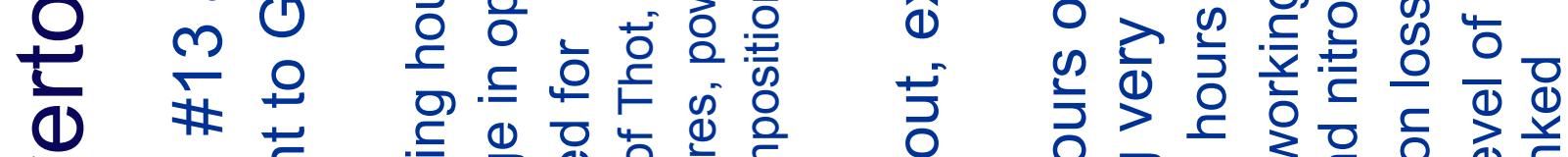

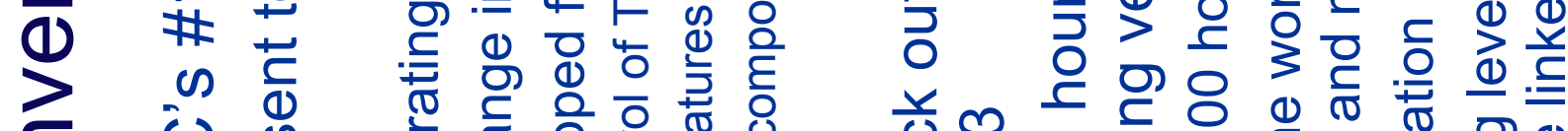

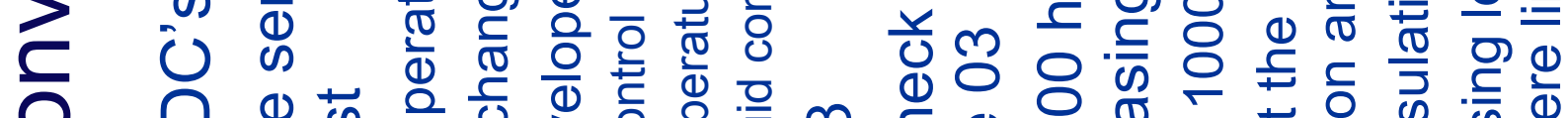

010 అ

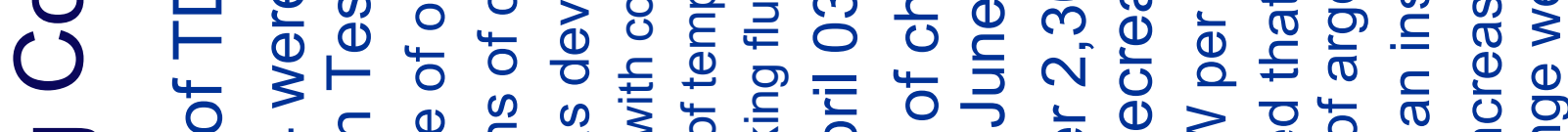

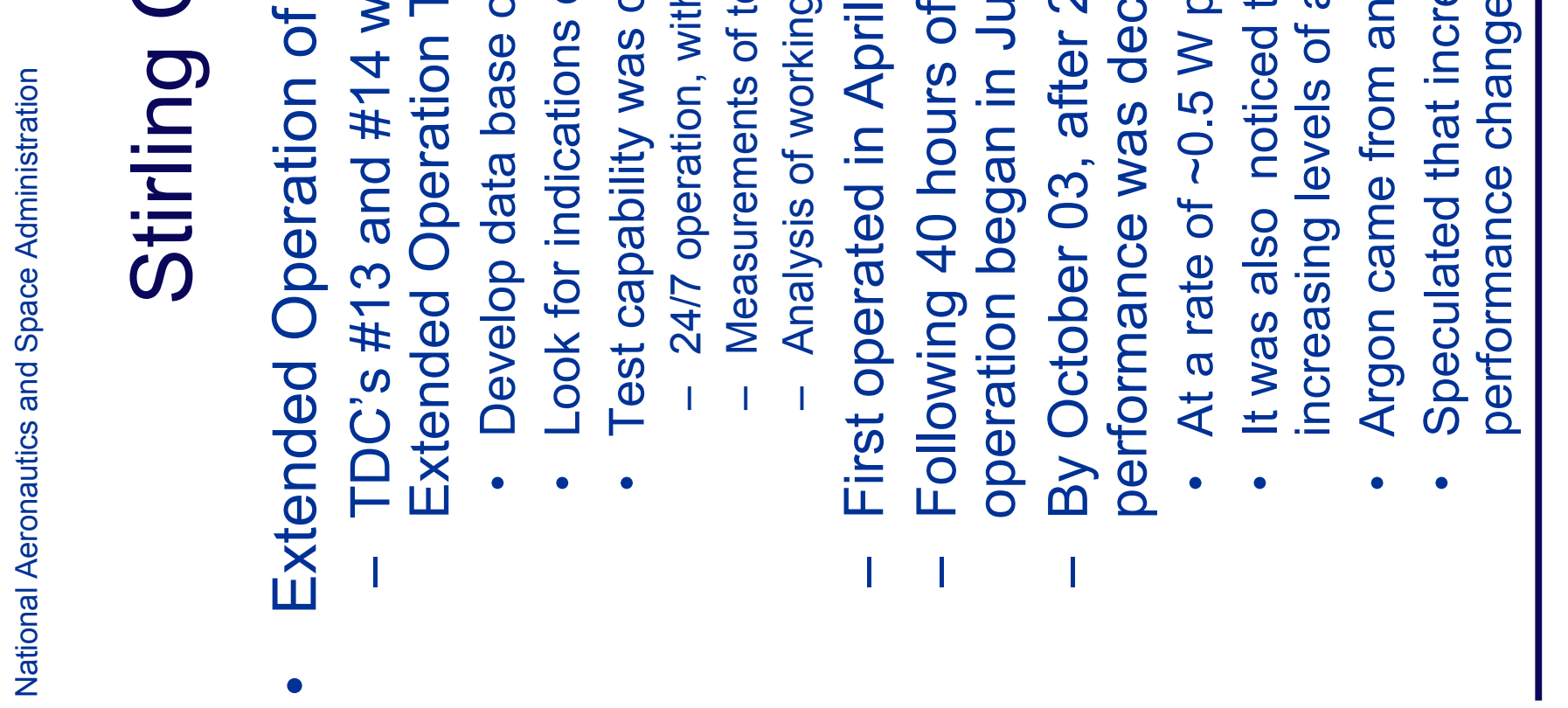



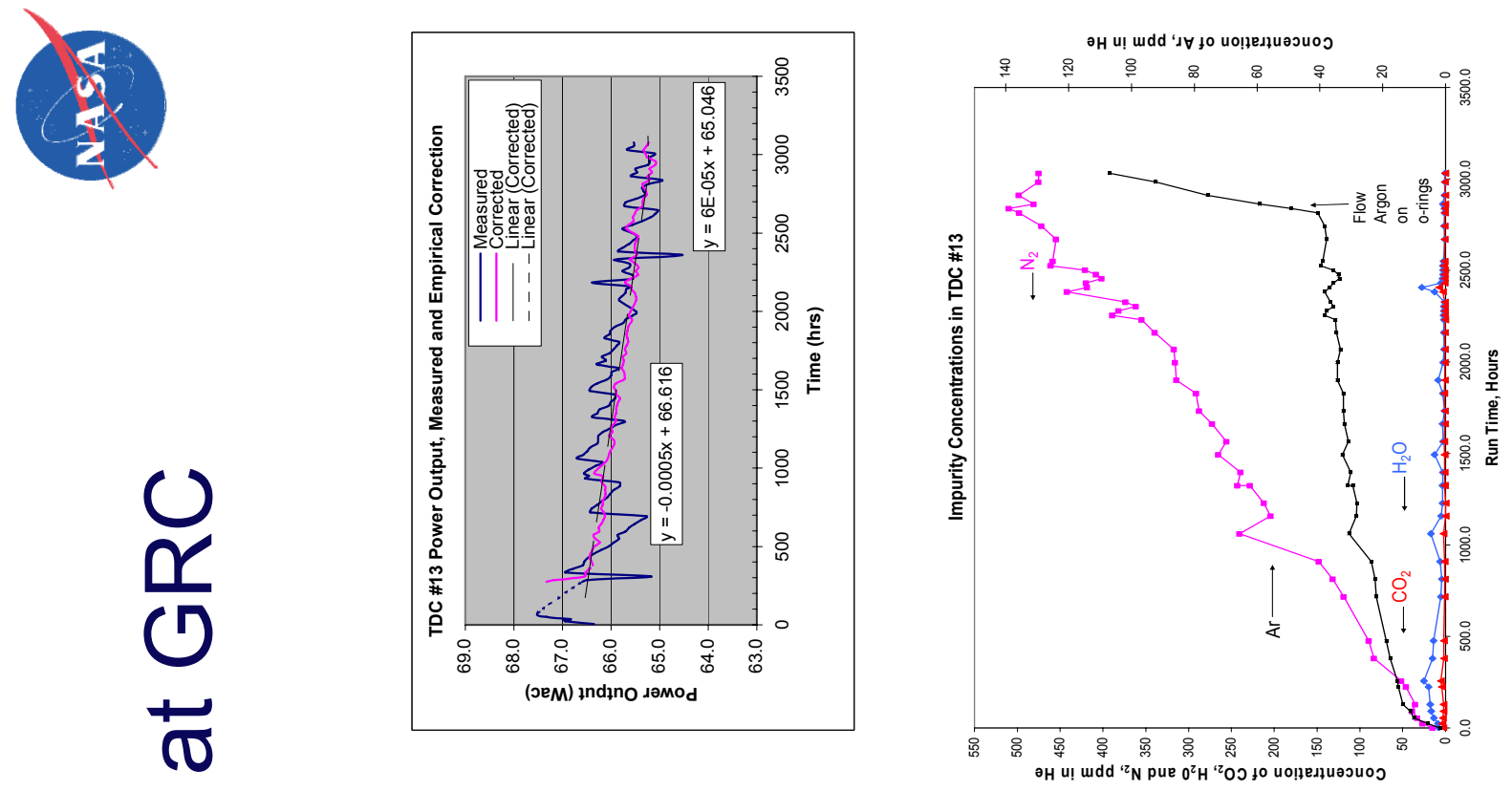

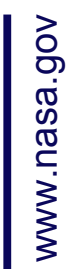

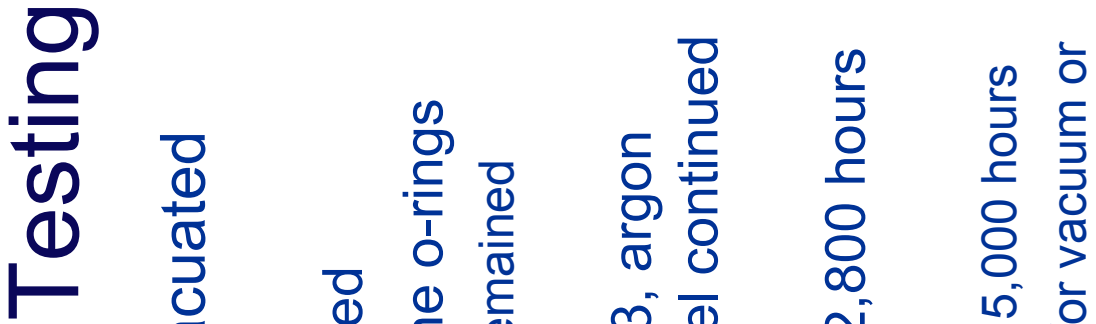

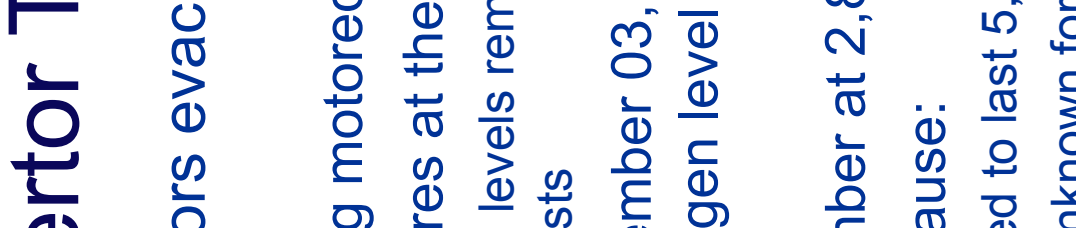

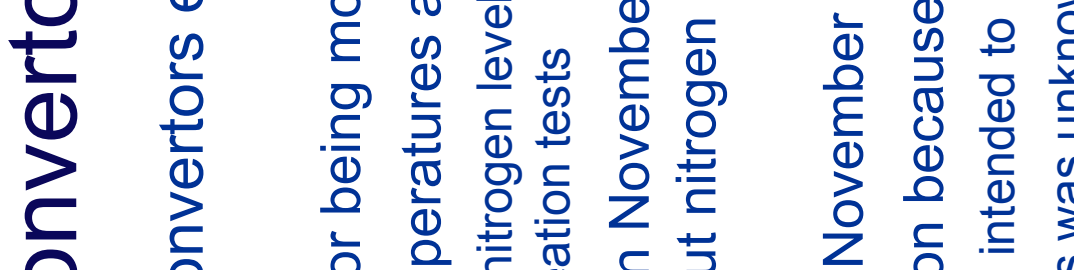

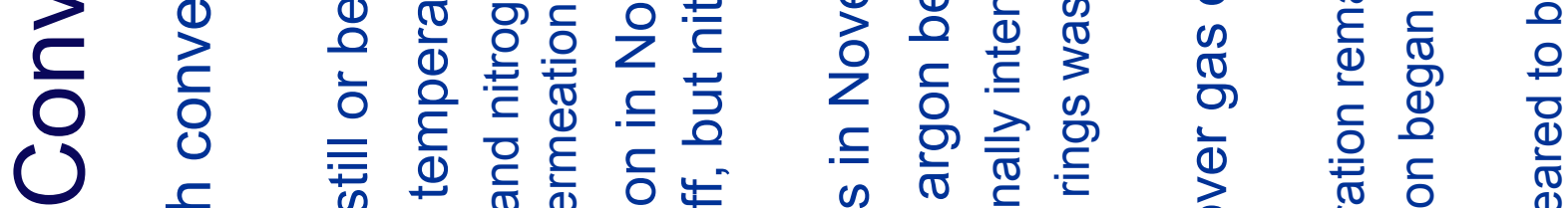

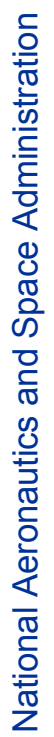

व

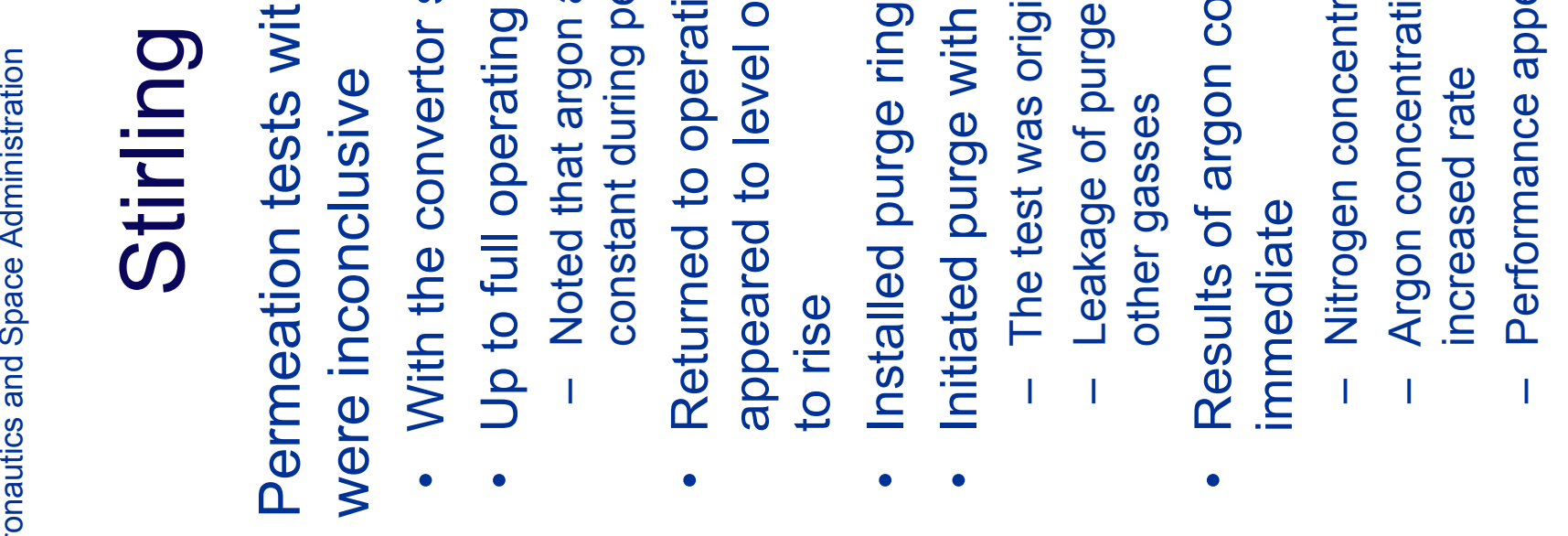




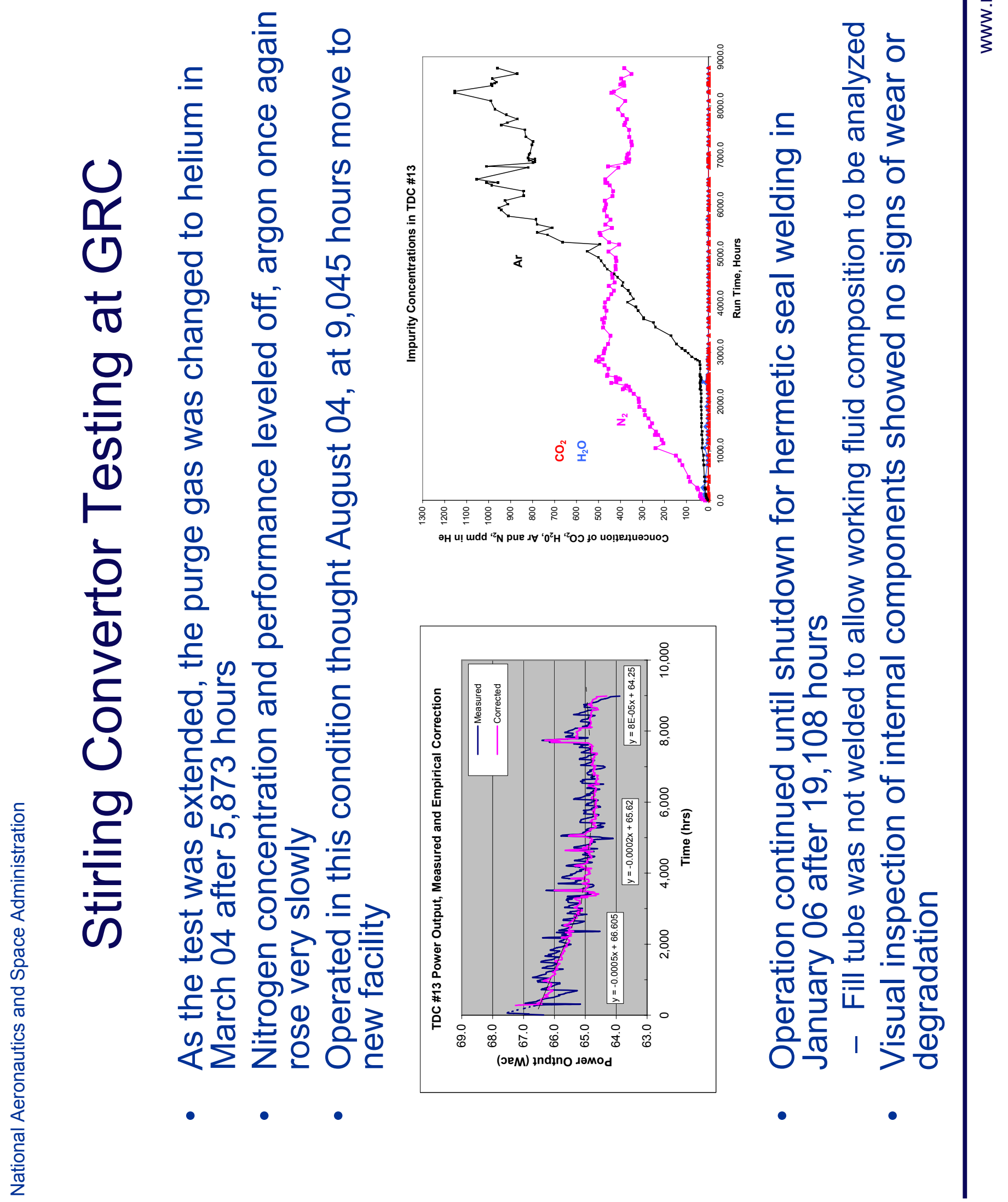



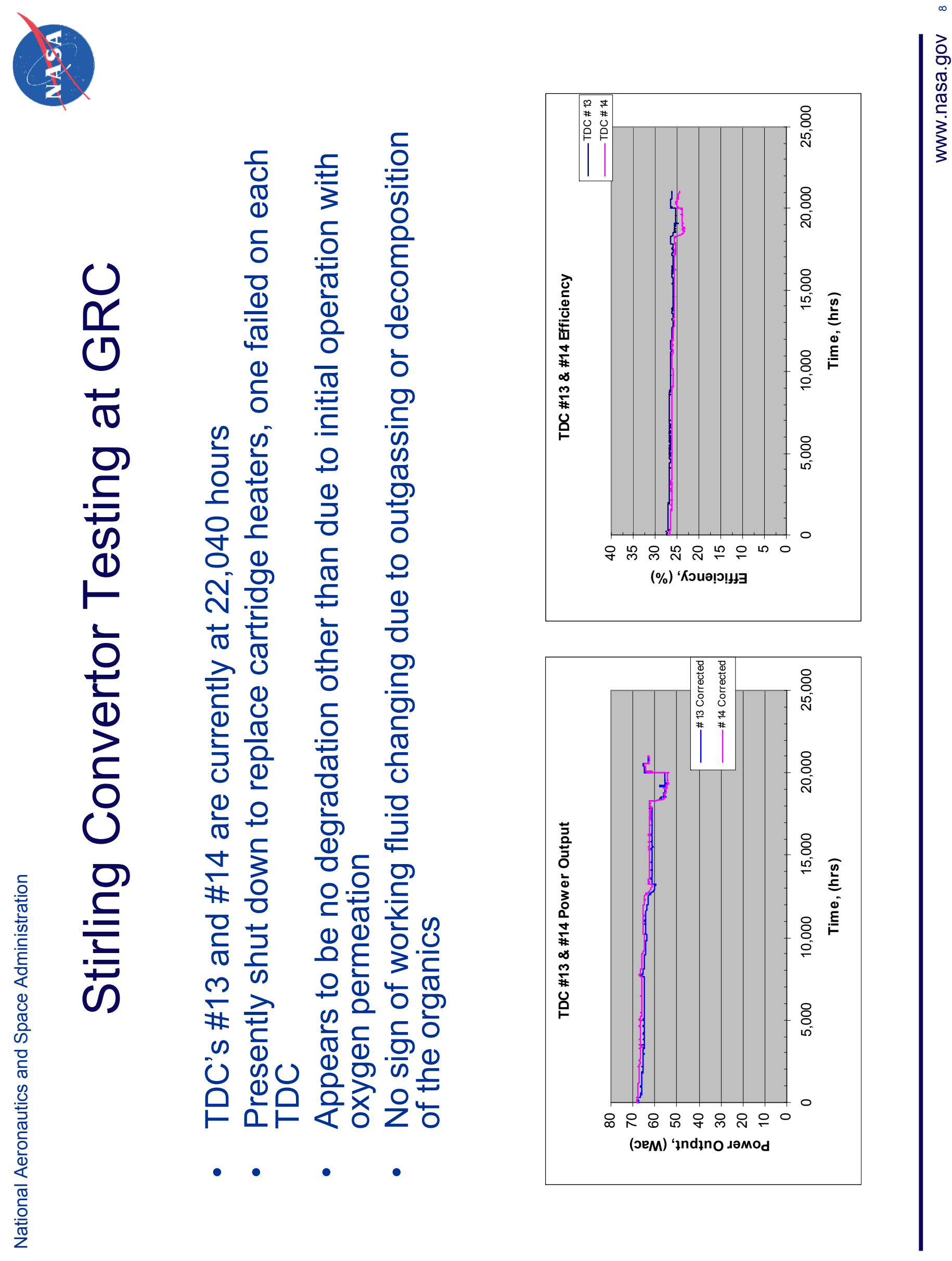
U

웅

(1)

$+\infty \quad$ ए

D बे फै

$\underset{+\infty}{\infty} \frac{\Omega}{2}$

$10+$

(1) $\quad 0$

$\frac{\varepsilon}{0}$

0 ॠ

(1) 으

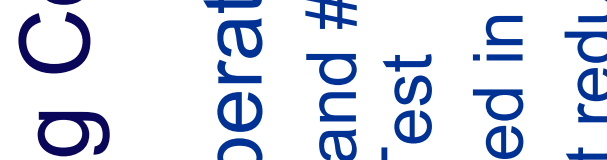

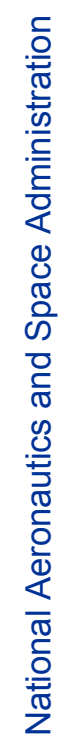

(1) 0

$\frac{1}{0}$

(1)

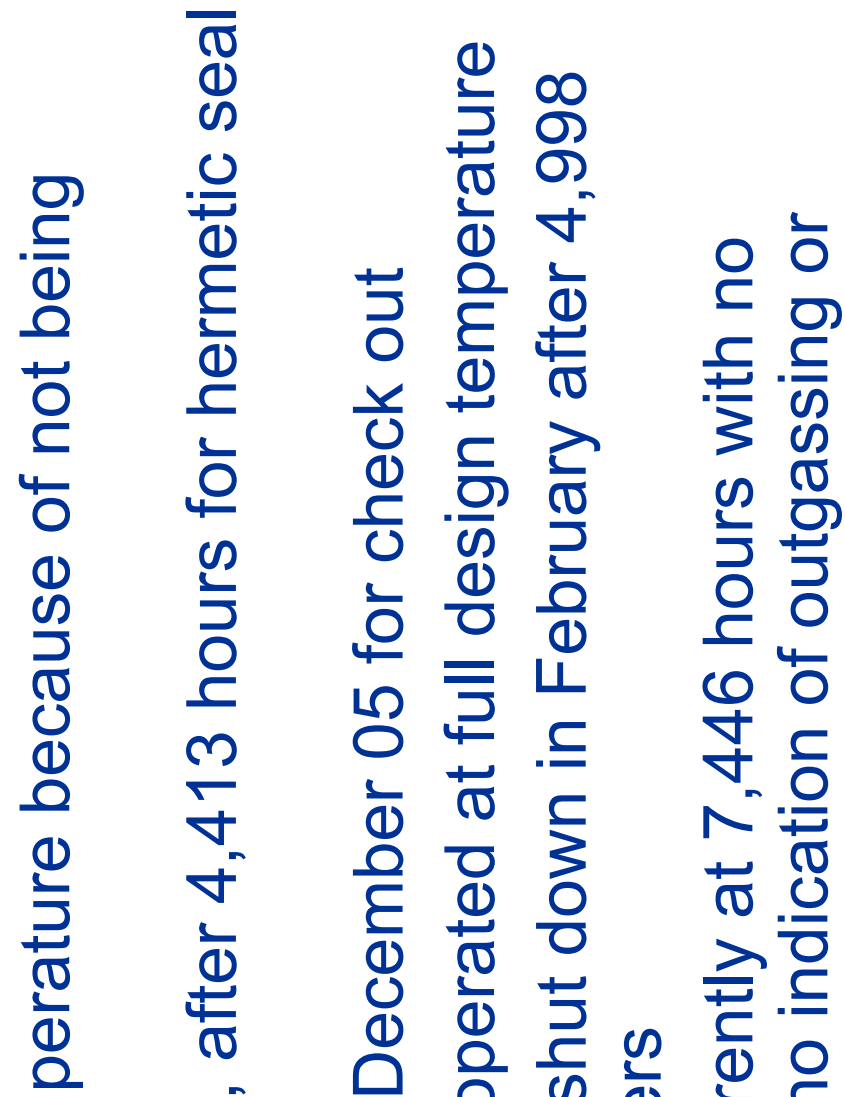

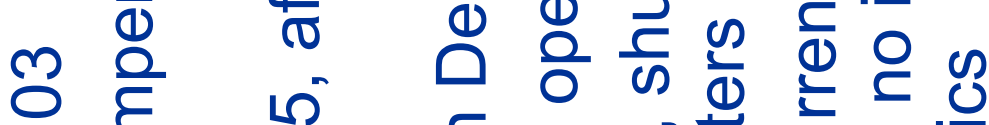
. 6 i

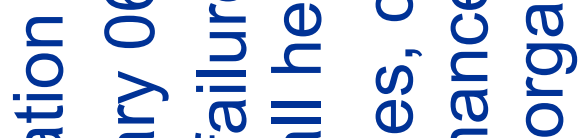

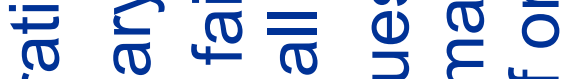
đ) 은 워 은

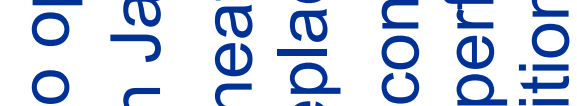
의 $ᄃ \subseteq \frac{0}{1}$ o

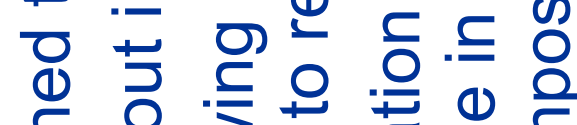
둘 0 후

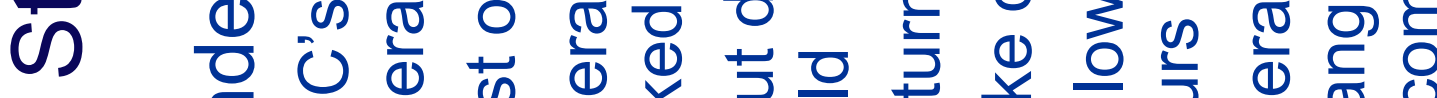
(1)

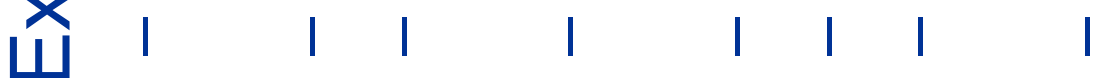




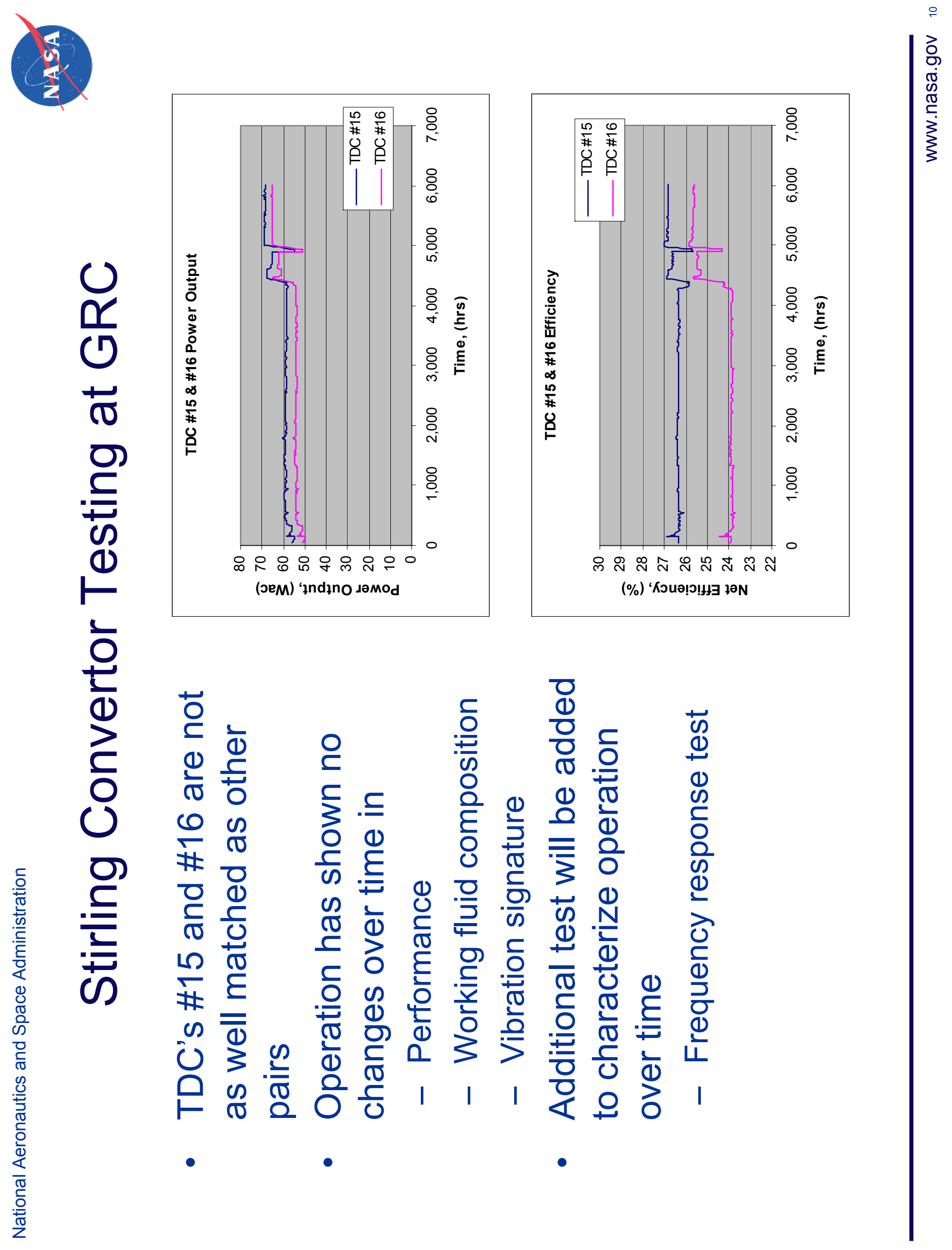




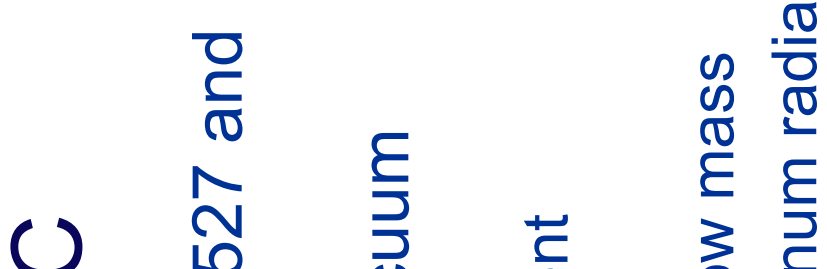

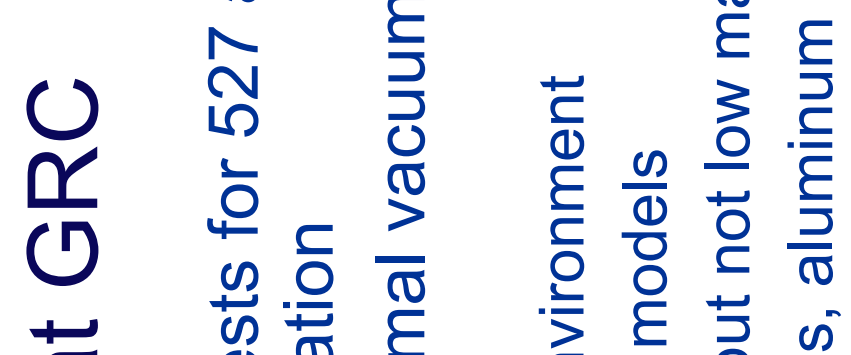

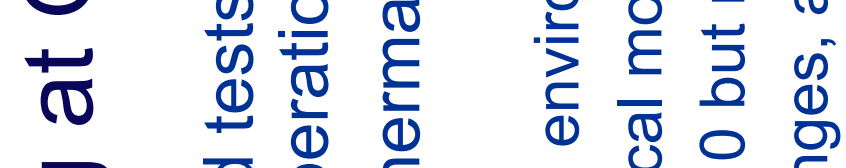

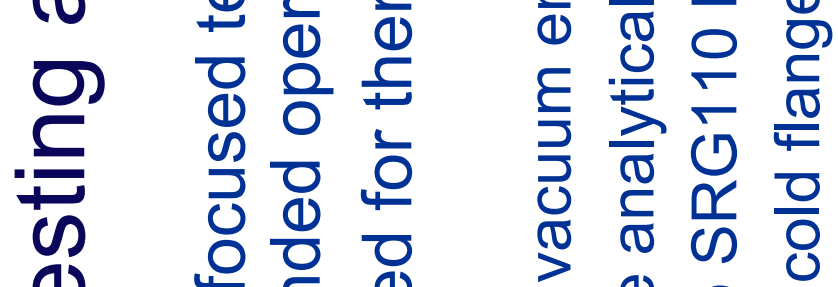

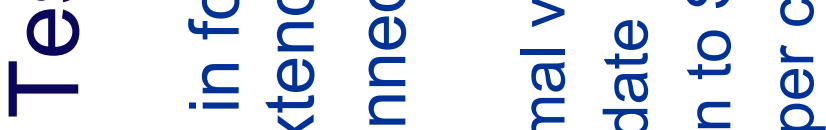

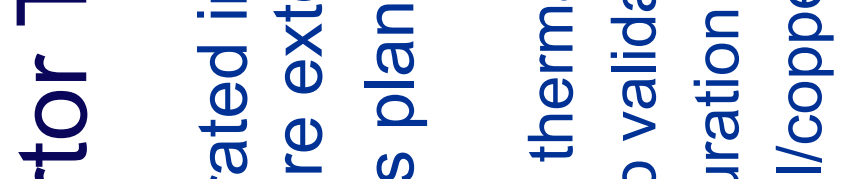

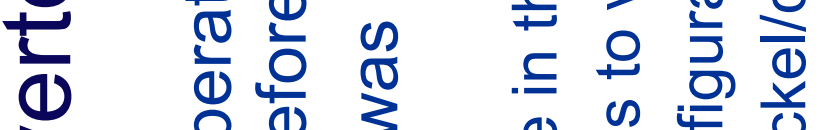

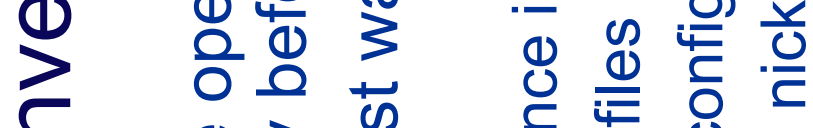

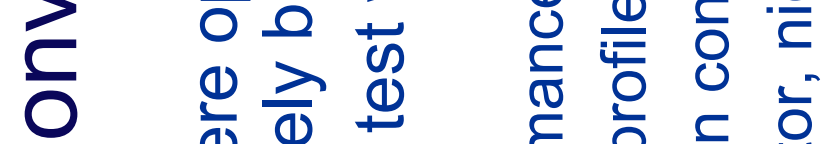

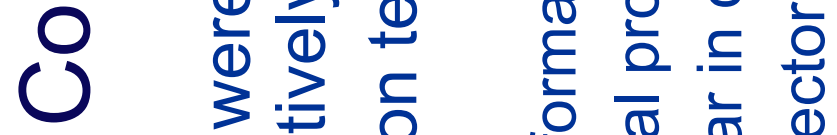

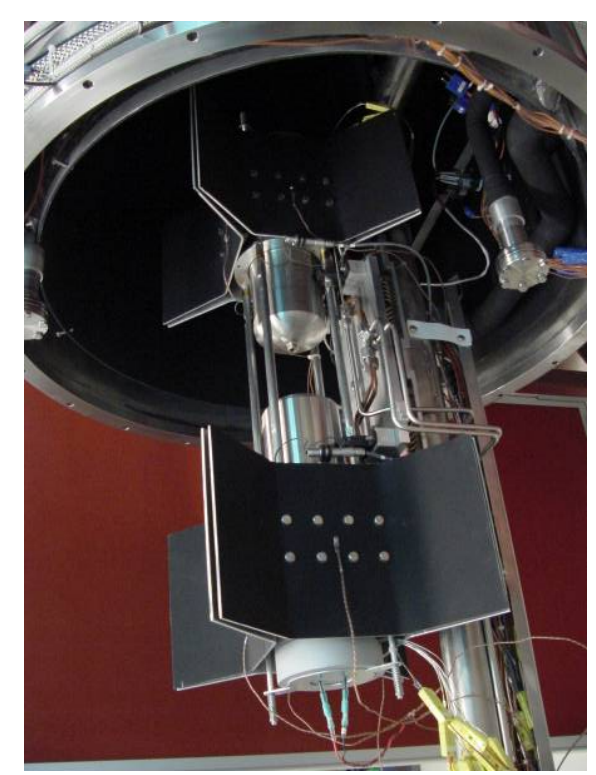

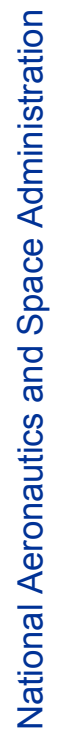

\#

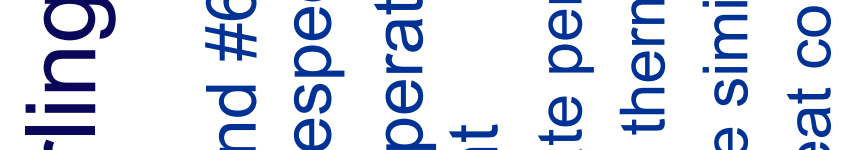

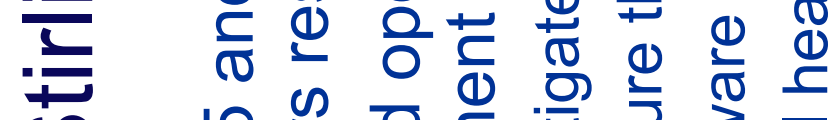

1 \#

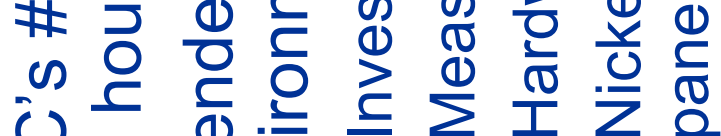

U

ம 
C

(1) ⿺辶)

$+\frac{Q}{\varepsilon}$

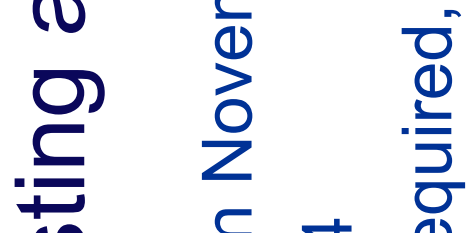

() 드 オ

(1) हே ป ษ

- ब) है

+

(1) 를 을

$>\quad 0 \square \quad \frac{}{0}$

$\approx \quad$ তে $\subseteq \underline{\underline{U}}$

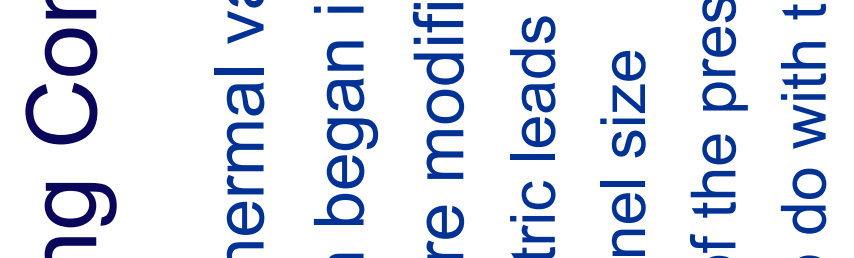

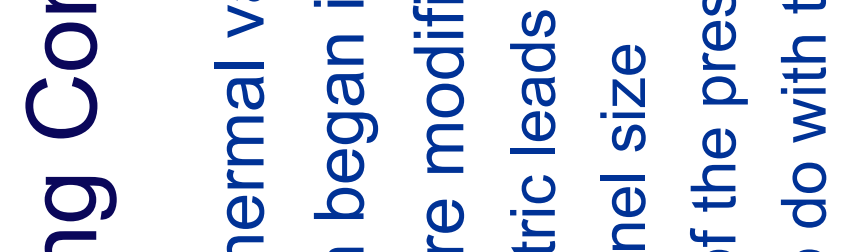

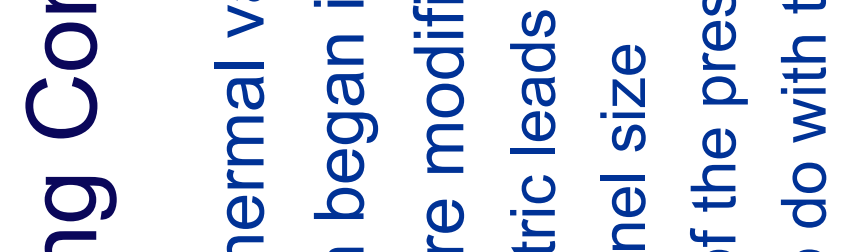

든 든

드 드음

프

क

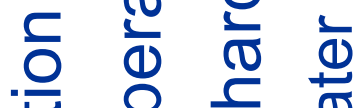

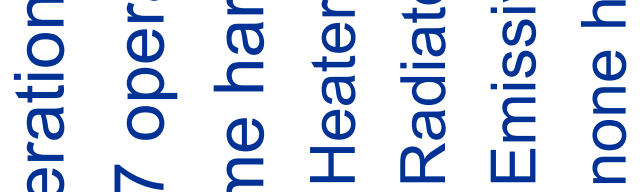

○ั §
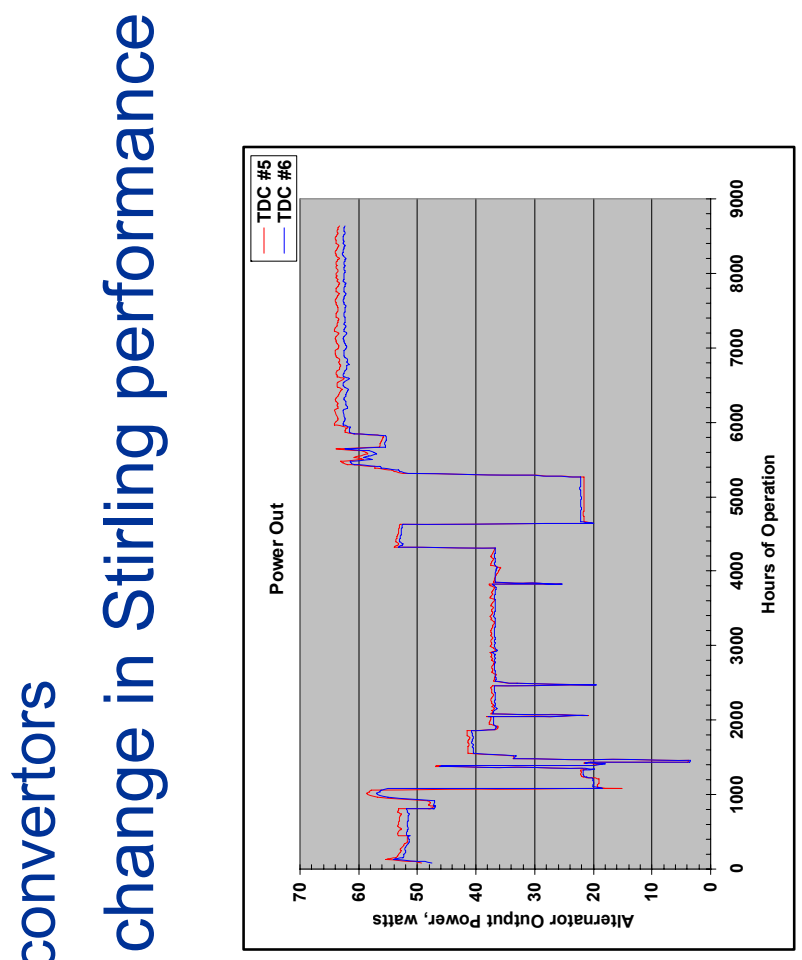

(⿻)

\竞

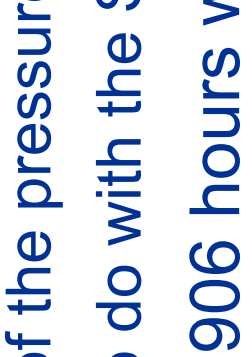

$\infty$

त

文

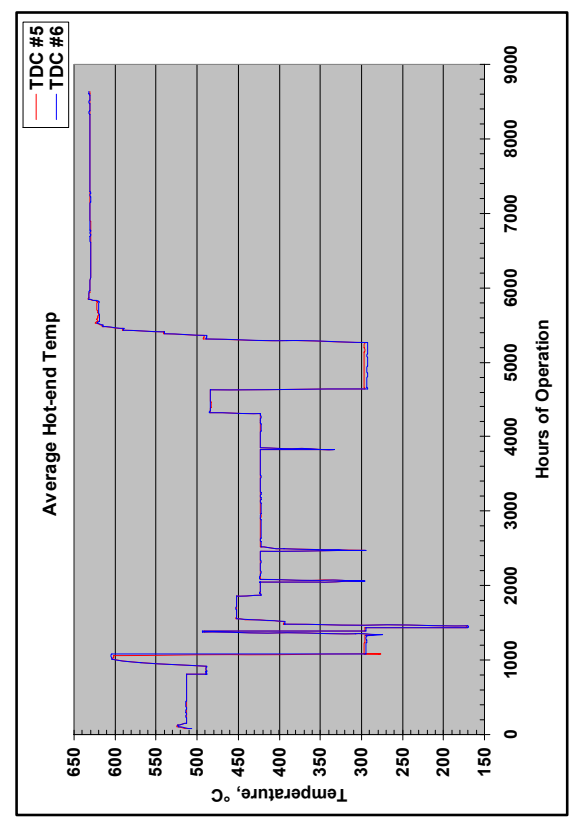

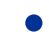




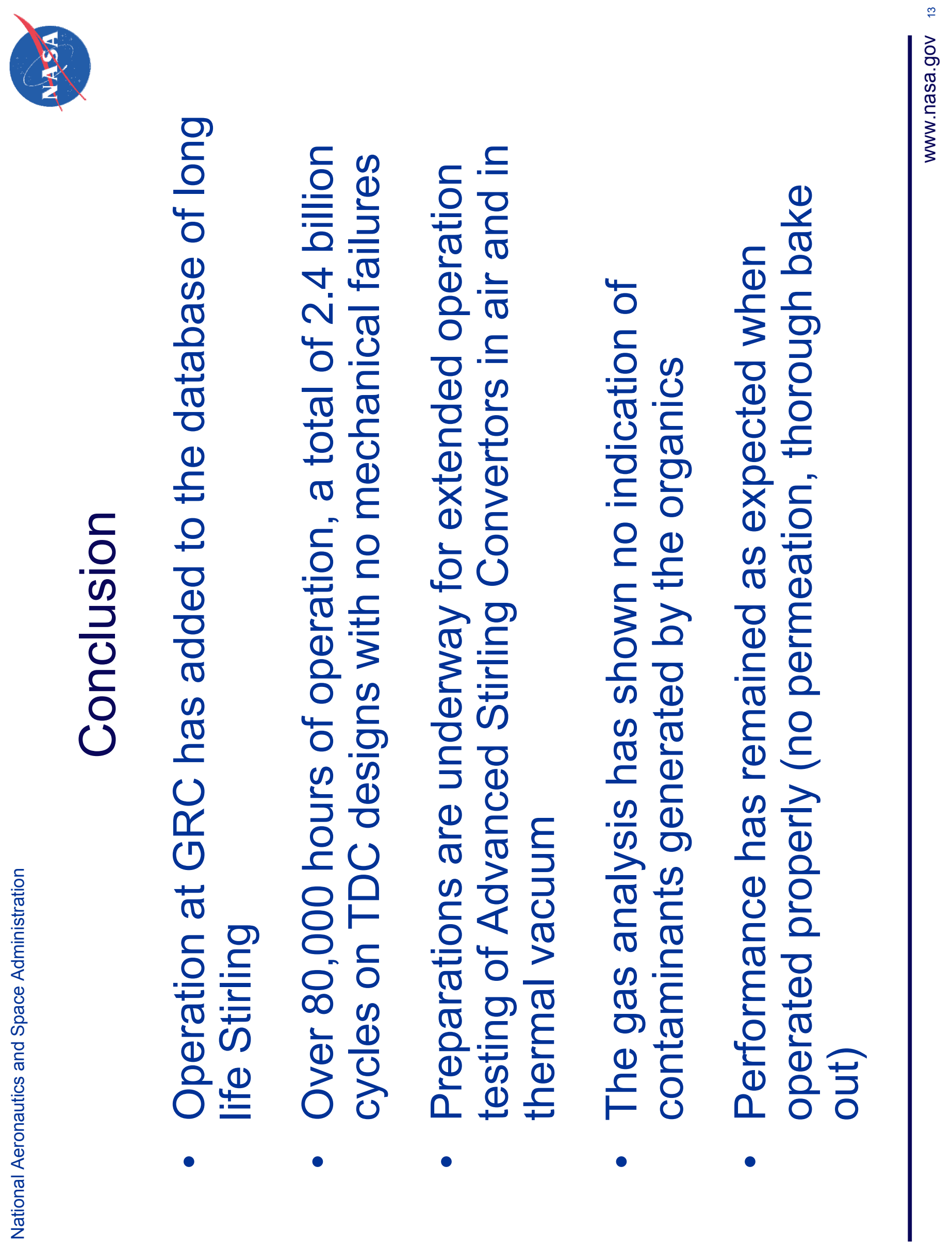

